\title{
Transtorno de Déficit de Atenção e Hiperatividade: implicações para a constituição leitora do aprendiz
}

\section{Attention Deficit Hyperactivity Disorder: implications for the reader constitution}

Rita de Cassia Fernandes Signor*

Universidade Federal de Santa Catarina / Hospital Infantil Joana de Gusmão

Florianópolis, Santa Catarina, Brasil

Resumo: O objetivo deste artigo é, por meio de um relato de caso, demonstrar as implicaçōes do diagnóstico de TDAH para a constituição leitora do aprendiz. Para tanto, apresentamos a história de Miguel, estudante do $6^{\circ}$ ano do ensino fundamental e portador do diagnóstico de TDAH desde os 7 anos de idade. Para a geração dos dados, foram realizadas entrevistas com o menino, seus professores e sua mãe, além de avaliação de leitura e escrita e pesquisa documental. Os dados foram analisados conforme a perspectiva sócio-histórica. Os resultados revelam que a internalização da condição de desatento e agitado influenciou desfavoravelmente a formação leitora da criança. Conclui-se que a escola, antes de encaminhar o aluno considerado muito ativo para profissionais de saúde, poderia acolhê-lo em sua singularidade, promovendo, entre outras ações, a sua inserção em práticas de leitura e escrita significativas.

Palavras-chave: TDAH; Subjetividade; Constituição leitora.

Abstract: The aim of this article is, by means of a case report, demonstrating the implications of the diagnosis of ADHD for the learning reader's constitution. For this, we present story of Miguel, a student of the 6th grade of the elementary school and be are for the diagnosis of ADHD since the age of 7 . To generate the data, interviews were conducted with the boy, his teachers and his mother, as well as the evaluation of his reading and writing, and a documentary research. The data have been analyzed according to socio-historical perspective. The findings reveal that the internalization of the inattentive and restless condition unfavorably influenced the child's reader constitution. It is concluded that the school, before forwarding the student considered very active for health professionals, could accept him in his uniqueness, promoting, among other actions, their integration in significant reading and writing practices.

Keywords: ADHD; Subjectivity; Reader Constitution.

* ritasignor@gmail.com 


\section{Introdução}

Os "sintomas" do chamado Transtorno de Déficit de Atenção e Hiperatividade (TDAH) já foram associados à Lesão Cerebral Mínima (LCM), na década de 1940, e à Disfunção Cerebral Mínima (DCM), nos anos 1960. No entanto, a insatisfação com esses termos fez surgir um conceito para a hiperatividade que foi definida da seguinte forma: "a criança com hiperatividade é aquela que conduz suas atividades em uma velocidade acima do normal observada na criança média, ou que está sempre se movimentando, ou ambos" (BARKLEY, 2006, p. 20). Para Barkley (2006), essa explicação foi considerada mais adequada uma vez que se baseou no comportamento observável das crianças, "em vez de algum mecanismo etiológico subjacente ao cérebro, que não poderia ser observado" (p. 20). Foi nessa época que a definição de hiperatividade apareceu na nomenclatura diagnóstica do Manual Diagnóstico e Estatístico de Transtornos Mentais (DSM-II, American Psychiatric Association, de 1968).

$\mathrm{Na}$ década de 1970, o traço desatenção foi considerado mais relevante do que o de hiperatividade para explicar as dificuldades das crianças com o chamado transtorno hipercinético, favorecendo o surgimento do Transtorno de Déficit de Atenção - TDA - no DSM III (1980). Em 1987, em decorrência de estudos em que questionaram a prevalência do sintoma da desatenção, o DSM-III sofreu uma revisão (DSM-III- R) e o TDA sofreu nova mudança terminológica, surgindo, então, o TDAH (BARKEY, 2006).

Embora o caráter orgânico do TDAH nunca tenha sido comprovado, é visto por muitos pesquisadores da corrente organicista ${ }^{1}$ como um transtorno neurobiológico que gera sinais e sintomas de hiperatividade, impulsividade e desatenção. Segundo a hipótese neurobiológica, haveria, em decorrência de uma falha genética, um aporte insuficiente de neurotransmissores ao cérebro. Para corrigir essa "falta", são prescritos, muitas vezes, medicamentos estimulantes, como o metilfenidato.

O diagnóstico de TDAH é pautado em características que podem ser vistas no comportamento do indivíduo. O DSM é um manual de psiquiatria americano bastante usado no Brasil por seguidores da vertente organicista.

\footnotetext{
${ }^{1}$ Esta é a visão divulgada pela Associação Brasileira de Déficit de Atenção. Para detalhes, consultar a página desta Associação na internet: www.abda.org.br. Vale dizer que existem outras explicações organicistas/cerebrais para o TDAH. Citá-las fugiria ao escopo deste trabalho.
} 
Dentre os sinais apontados nesse manual estão: "com frequência apresenta esquecimento em atividades diárias"; "frequentemente agita as mãos ou os pés ou se remexe na cadeira"; "está frequentemente a mil ou muitas vezes age como se estivesse a todo vapor"; "frequentemente fala em demasia"; "frequentemente interrompe ou se intromete em assuntos alheios" etc. Há uma lista de 18 sintomas ( 9 para hiperatividade e impulsividade e 9 para desatenção) e o diagnóstico é dado muitas vezes em função de um critério quantitativo.

Destaca-se que existem diferentes visões sobre esse (suposto) transtorno. Diferentemente do que preconizam os organicistas, pesquisadores da vertente sócio-histórica, pautados no conceito de medicalização $o^{2}$, acreditam que há uma série de razões que podem interferir no desenvolvimento da criança e que necessitam ser investigados. O que se nega, sob esse olhar, é que o chamado TDAH seja decorrente de uma condição neuro(bio)lógica do sujeito. Entende-se que as dificuldades que se manifestam na escola são construídas socialmente. Conforme Moysés (2001), esse "transtorno” pode ser uma resposta da criança que sinaliza que algo não está bem. Considera-se, ainda, a imensa diversidade manifesta nos modos de ser, pensar, agir, viver, o que significa que em qualquer situação de grupo sempre haverá os mais ativos, os menos ativos, os mais falantes, os menos falantes, os que levantam mais da carteira, os que levantam menos, os que perguntam mais, os que perguntam menos, sem que isso seja, de fato, uma doença neuropsiquiátrica.

Questiona-se ainda a fragilidade de critérios diagnósticos que medicalizam alunos, que por serem mais ativos do que uma média tida como normal, ou com ritmos de aprendizagem diferentes, passam a vivenciar a estigmatização na escola, com todas as implicações desse processo para a constituição da subjetividade e, por conseguinte, para a aprendizagem e socialização do aluno (MOYSÉS; COLLARES, 2011; SIGNOR, 2013).

Importante lembrar que as dificuldades de leitura e escrita costumam acompanhar o dito transtorno. A pesquisa de Silva (2006) revelou que $87,5 \%$ das crianças com esse diagnóstico têm dificuldades escolares. Para Cunha et al. (2013), haveria uma base neurobiológica ocasionando alterações

\footnotetext{
${ }^{2}$ Medicalização é um conceito que está relacionado à transformação de questões sociais em aspectos de ordem da saúde. Por exemplo, se uma criança com dificuldades para aprender a ler - e plenas condiçóes cognitivas - recebe o diagnóstico de dislexia, entende-se que essa criança foi medicalizada. Para aprofundamento do conceito, ver Conrad (2007).
} 
em mecanismos cognitivos que estão associados com a aprendizagem, tais como atenção sustentada, funções executivas, déficit de inibição motora, entre outros. Esses déficits ocasionariam dificuldades nas habilidades metalinguísticas na fase pré-escolar.

Distantes dessas considerações acerca da aprendizagem da escrita, os estudiosos da contracorrente consideram o contexto mais amplo que envolve as chamadas dificuldades escolares, ou seja, alertam que é preciso que se problematizem os aspectos sociais e educacionais que permeiam a realidade brasileira. Por exemplo, ao se considerar os dados de alfabetismo do povo brasileiro, é possível que se reflita sobre a qualidade do sistema educativo neste país e em que medida o sistema produz os chamados distúrbios de leitura e escrita. Como coloca Demo (2012), muitos alunos brasileiros não sabem ler e escrever porque essas habilidades não são desenvolvidas em sua plenitude na escola.

Mediante um sistema educacional que funciona precariamente, é possível entender o índice elevado de encaminhamentos de alunos aos consultórios de profissionais de saúde para que recebam um diagnóstico ("o laudo") sobre suas dificuldades. A ineficácia do sistema educacional se sustenta na sua permeabilidade ao discurso supostamente científico da área da saúde.

Cabe dizer que o sujeito não pode ser reduzido (como prevê a tradição positivista) a um cérebro apartamento das suas inserções socioculturais. Consideramos que os sujeitos são multifacetados, pois constituídos em múltiplas dimensões, atravessados por suas interações sociais e, desse modo, é necessário avaliar em profundidade a qualidade das interações sociais pelas quais a criança está submetida para que se faça um diagnóstico preciso do que pode estar dificultando o processo da escolaridade (SIGNOR, 2013; SIGNOR, 2013a; SIGNOR; SANTANA, 2015).

Vale dizer que, se o aluno for inserido em práticas discursivas desfavoráveis ao seu desenvolvimento na escola, é possível que adentre a um processo de baixa autoestima em relação à sua condição de sujeito/aprendiz. Dizeres como não sei, não consigo, escrevo errado, sou distraído, sou agitado, ler é chato, escrever é chato, detesto ler começam a fazer parte do discurso do sujeito, distanciando-o cada vez mais da linguagem escrita e impossibilitando o avanço das suas condições de letramento (SIGNOR, 2013a).

É possível imaginar que crianças distantes da escrita, muitas vezes carregando estigmas de portadoras de dificuldades possam desenvolver 
sintomas na área da linguagem escrita, como, por exemplo, uma rejeição em ler e produzir textos, o que poderia conduzir às chamadas "dificuldades de leitura e escrita”, uma vez que para ler e escrever bem é necessário estar inserido em práticas significativas mediadas pela leitura e pela escrita (SIGNOR; SANTANA, 2015).

A partir desses apontamentos, o objetivo deste artigo é apresentar a avaliação fonoaudiológica, pautada no paradigma sócio-histórico, de um menino de 12 anos de idade e com diagnóstico de TDAH. O estudo se justifica uma vez que para a criança tida hiperativa/desatenta ocorrem implicações subjetivas que podem incidir nos processos de letramento (aprendizagem da escrita e constituição leitora). Tais implicações ocultamse nas avaliações tradicionais pautadas em testes-padrão, mas necessitam ser consideradas, pois um procedimento clínico eficaz envolve sobremaneira (res)significar a relação da criança com a linguagem escrita.

\section{Método}

Esta pesquisa se constitui em estudo de caso, pesquisa empírica, qualitativa, do tipo transversal, inserida em um paradigma teóricometodológico de cunho sócio-histórico. Para a pesquisa foram selecionados cinco estudantes (do $5^{\circ}$ e $6^{\circ}$ anos) da rede pública de ensino da região Sul do Brasil. Os critérios de seleção dos sujeitos foram: alunos com diagnóstico médico de TDAH; crianças acima do $3^{\circ}$ ano do ensino fundamental (para que houvesse um volume suficiente de dados para melhor composição do "histórico"); e, por fim, que houvesse disponibilidade e interesse da família em participar da pesquisa. Para este artigo, apresenta-se somente parte da história de Miguel (nome fictício), 12 anos de idade, estudante, à época da pesquisa, do $6^{\circ}$ ano do ensino fundamental.

Os procedimentos da pesquisa envolveram: entrevistas com a mãe da criança e com a criança, avaliação fonoaudiológica individual ${ }^{3}$, observação do aluno em sala de aula por um período de uma semana, entrevistas com professores, avaliação das condições de letramento de todos os alunos da sala (aplicação de questionário e observação de produção textual) e pesquisa documental (pareceres avaliativos da escola - atuais e pregressos, agendas,

\footnotetext{
${ }^{3}$ Miguel, anteriormente à sua participação nesta pesquisa, não havia sido avaliado por profissional da fonoaudiologia. As avaliações mencionadas neste trabalho são: psicológica, médica e pedagógica (pareceres avaliativos da escola).
} 
cadernos, livros, pastas com atividades). Os dados foram registrados por meio de gravação em áudio e diário de campo e analisados via referencial sócio-histórico (BAKHTIN, 2006; VYGOTSKY, 2010).

O estudo foi aprovado pelo Comitê de Ética em pesquisa da Universidade de Santa Catarina sob processo número 94.405/12. Foram assinados os Termos de Consentimento Livre e Esclarecido por todos os participantes da pesquisa.

\section{Apresentação da criança}

Miguel é um menino de 12 anos de idade e frequenta o $6^{\circ}$. ano do ensino fundamental em uma escola situada próxima à sua residência (localizada em uma região nobre da cidade). É filho adotivo e tem um irmão biológico (por parte de mãe) de 10 anos de idade, Ricardo. Os irmãos haviam sido adotados (à época do estudo) há seis anos - Miguel tinha 6 anos e Ricardo 4 anos de idade. Anteriormente à adoção, Miguel e seu irmão estavam em um abrigo para crianças há um ano, pois haviam sido retirados da mãe biológica (MB) em virtude de maus-tratos. Durante esse ano em que permaneceram no abrigo, a MB não foi visitar os filhos nem manifestou qualquer desejo em retomar a guarda deles. Segundo a mãe adotiva (Júlia), as crianças, quando estavam sob a guarda da $\mathrm{MB}$, permaneciam em casa durante o dia, às vezes à noite, sozinhos, sem comida, nem banho. Os irmãos se escondiam no mato e, por vezes, eram encontrados pela polícia.

Segundo Júlia, Miguel tem lembranças dessa fase, mas ele não se refere a MB como mãe, ele diz "aquela mulher". No relatório psicológico cedido pela mãe constava a informação de que Miguel havia, inclusive, trocado de nome após ser adotado:

O pequeno Ricardo [o irmão] demonstrou resistência no início do tratamento, mas logo vinculou-se, já o menino Miguel desde o início demonstrou interesse em falar sobre a adoção e resolver a situação, que para ele já estava definida: "Sou o Miguel, não sou mais o Fernando e meu pai e minha mãe são Júlia e José Paulo e pronto. Eu sou filho deles". [Excerto do Relatório psicológico]

Júlia tem 42 anos e José (o pai adotivo) tem 55 anos de idade. Ela é pedagoga, pós-graduada em psicopedagogia, e ele é taxista. Por conta da morosidade do processo de adoção, haviam resolvido adotar duas crianças de uma vez só, para não terem de passar pelo mesmo processo duas vezes. 
Não foi possível obter informações sobre a época da educação infantil, pois foi o período em que Miguel estava sob a guarda da MB e depois no abrigo. $\mathrm{O}$ menino realizou o $1^{\circ}$ e $2^{\circ}$ ano em uma escola pública municipal, tendo tido a mesma professora nesses dois anos. A partir do $3^{\circ}$ ano foi para o atual colégio (escola pública considerada de referência). Estuda no período vespertino, mas tem muitas atividades no período matutino: educação física e aulas de reforço (atendimentos extras que são oferecidos pela escola a todos os alunos que queiram ou precisem).

Miguel recebeu o diagnóstico médico de TDAH aos 7 anos de idade, um ano após ter sido adotado. Segundo Júlia, no abrigo Miguel era tido como uma criança normal, mas "logo que entrou para a escola [aos 6 anos e 9 meses] teve diagnóstico de que tinha alguma coisa.” A mãe revelou que recebia constantes reclamações a respeito do filho "toda hora eles me ligavam e falavam 'o Miguel brigou na escola, o Miguel não para quieto'...”, mas que ela não via nisso um problema sério uma vez que "no primeiro ano eles são muito ativos", conforme suas palavras. Em função disso, a mãe optou por oferecer florais ao filho, mas como as queixas da escola persistiram, ela acabou por levar a criança ao neurologista, que diagnosticou o transtorno. Como forma de tratamento para o TDAH, Miguel ingere medicação controlada e realiza atendimento com uma psicóloga.

A seguir, a título de ilustrar como o aluno era referenciado, apresentase um dos pareceres de quando Miguel tinha 7 anos de idade:

Quanto à escrita, reconhece algumas letras em seu nome e alguns nomes significativos como de seus pais e seu irmão.

Gosta de relatar fatos do seu cotidiano familiar. Observa-se que tem um pouco de dificuldade de esperar a vez de falar. Interessa-se por jogos e brincadeiras. Gosta de brincar no parque.

Dificuldade para ficar sentado durante muito tempo. Distrai-se e se esquece facilmente de tarefas e compromissos.

Em sua escrita espontânea coloca letra sem valor sonoro, não identificando nenhuma sílaba. Vem demonstrando interesse e contato com as letras móveis.

Tem um pouco de dificuldade para resolver cálculos mentais bem como para reconhecer números. Procura evitar atividades que necessitam de os utilizar.

(02) [Parecer avaliativo da primeira escola, grifo meu] 
Em outros pareceres avaliativos havia comentários do tipo: "continua sendo lembrado a concentrar-se mais". Na atual escola as reclamações continuaram. A mãe relata que a professora do $3^{\circ}$ ano "só via coisa negativa" e em função de seu comportamento considerado agitado, o filho "ficava muito fora da sala", tomando chazinho. E que mesmo medicado, ela era chamada direto na escola também.

Cabe dizer que Miguel teve dificuldades no processo de alfabetização sem ter qualquer alteração de ordem constitutiva que pudesse justificar as dificuldades apresentadas. Ainda, Miguel traz em seu discurso as marcas geradas pelo processo de medicalização sofrido. Considera-se "diferente", no sentido pejorativo do termo, relata que é "anormal em todos os sentidos" e que "não consegue se concentrar na aula", mesmo sob efeito de medicação. A criança adentrou em um processo de exclusão escolar que se perpetua até a atualidade.

Ressalte-se que durante o período de observação em sala de aula, não foram observadas pela pesquisadora diferenças entre Miguel e as demais crianças no quesito comportamento. Inclusive, em entrevista, os professores relataram que a turma toda era muito agitada ${ }^{4}$. Foi verificado, no entanto, que Miguel é excluído das relaçóes com os colegas.

\section{Avaliação de leitura e escrita}

Para a análise da leitura, foram utilizados três textos: a crônica $O$ melhor amigo e os contos $A$ árvore dos desejos e $A$ divisão dos gansos (vide anexos 1 e 2). Detemo-nos, abaixo, a mostrar o excerto relativo à discussão do texto A árvore dos desejos, de Rosane Pamplona. Cabe dizer que as respostas foram oralizadas, pois Miguel disse que não gostaria de escrevê-las porque escrever era, segundo suas percepçôes, algo "chato".

[Miguel lê o texto $A$ árvore dos desejos em voz alta]

P. (Pesquisadora) Agora me diz: porque João queria se matar?

M.(Miguel) Porque ele era infeliz.

P. Quem era o velho que apareceu para João?

M. Foi um feiticeiro.

\footnotetext{
${ }^{4}$ Importante assinalar que em parte do período de observação o menino não estava sob efeito de medicação estimulante, pois, em decorrência de reações indesejadas, a médica que o atendia estava promovendo a substituição.
} 
P. Qual foi a chance que o velho deu a João?

M. De ele...ele fez um desafio...

P. Qual foi o desafio?

M. De ele andar durante sete dias no mesmo lugar que o vento estava indo. E aí ele fez isso...e aí ele ia achar a mesma árvore que ele tava se enforcando e aí ele foi lá...aí ele achou uma igualzinha que o velho falou...e aí ele fez os desejos dele.

P. Quais foram os desejos dele?

M. Comida, bebida, um monte.

P. Comida...bebida...tem mais alguma coisa?

M. Posso ver? [Consultar o texto]

P. Pode.

M. [Procura] À vontade. [no texto estava escrito: "Quero comida e bebida à vontade"]

P. Quais seriam os seus desejos, Miguel?

M. Tudo que é eletrônico, novo, hum...uma mulher...e ia querer mais coisas também.

P. João tinha ou não tinha sorte?

M. Não tinha...porque ele era...não sei...

P. Não sabe. Não tá dizendo aqui?

M. Porque ele não arranjava emprego, ele não arranjava namorada e não conseguia comida.

P. O que aconteceu com João no final da história?

M. Ele pensou que a mulher dele ia devorar ele.

P. E?

$\mathrm{M}$ [silêncio]

P. Aqui tem 3 pontinhos...é pra você imaginar o final da história...

M. E aí ele desejou isso e aí aconteceu.

P. Aconteceu o que mesmo?

M. Que a mulher dele devorou ele.

P. Muito bem.

M. E era isso mesmo?

(03) [Avaliação da criança]

Pela avaliação da leitura, percebe-se que Miguel não teve problemas para compreender o texto lido, respondendo às perguntas que poderiam ser localizadas na superfície textual. Apenas a resposta à pergunta que questionava a identidade do velho, poderia ter sido feita remissão ao Senhor Destino. Contudo, "feiticeiro" remete ao final do conto, quando 
o protagonista pergunta se o velho não seria um feiticeiro. Justifica ainda o desfecho apresentado por Miguel, quando ele, acreditando na condição de feiticeiro do velho, alude ao fato de a mulher ter devorado João, o protagonista. Entretanto, preso ao sentido literal, ainda não realizou inferências; pelo menos não observáveis durante o processo de avaliação. A avaliação demonstrou aspectos processuais da leitura de Miguel, ou seja, que em detrimento da fluência e compreensão, necessita ser inserido de forma mais intensa em práticas de leitura e em situações de mediação, por meio de perguntas provocadoras, no sentido de levá-lo ao desenvolvimento dos processos de inferenciação.

Para a avaliação da escrita, foram realizadas três produções de texto, uma delas apresentada nesta seção. A primeira proposta partiu de construção de texto em conjunto ${ }^{5}$, que comporia um suposto diário virtual a ser postado em um blog que estava sendo desenvolvido pela pesquisadora. Como Miguel referiu durante a entrevista ter gostado da leitura do Diário de um banana, pensou-se que poderia ser uma forma de promover a motivação da produção escrita. Contudo, como a realidade retratada por ele, referente a um dia comum, não pareceu ser atrativa para que ele pudesse querer desenvolver um texto; foi sugerido, então, que se pensasse em um dia de sonho: um dia em que todos os desejos pudessem ser realizados, bastando apenas que se pensasse bem forte sobre eles. Seria, desse modo, a descrição de um dia imaginário para um diário de ficção. Abaixo, o texto está transcrito preservando-se as palavras dos autores. As letras em caixa alta representam a escrita da pesquisadora e as que estão em caixa baixa a de Miguel. Vejamos:

\section{SEGUNDA}

Hoje eu fui domir e alguêm veio e me falou que eu vou acorda e vai realizar tudo tudo que eu quizer.

ACORDEI. EM PRIMEIRO LUGAR, O CAFÉ DA MANHÃ. Penssei forte e derrepente tinha o chocotone. COMI O CHOCOTTONE E DEPOIS joguei PSP, nintendo DS, Ifhone, Smartfhone, tablet e uma metralhadora nerf. DEPOIS DE BRINCAR MUITO, FUI ALMOÇAR e pensei numa pizza. APÓS COMER A PIZZA, FUI PARA A ESCOLA. PENSEI BEM FORTE. Entrei na sala de aula fui me sentar no meu lugar e era a minha aula preferida, que era matemática.

\footnotetext{
${ }^{5}$ Em razão da rejeição para escrever; disse que não gostaria porque escrever era "chato".
} 
FIQUEI FAZENDOTODOS OS EXERCÍCIOS e não precizei de ajuda de ninguém. E eu na frente como todo mundo e ela lá atraiz conversando. A [THATI] VEIO ME PEDIR AJUDA, porque ela não sabia fazer o exercício e eu ajudei e depois ela me pediu em namoro e eu aceitei. FICAMOS CONVERSANDO NA HORA DO RECREIO e os meninos ficaram olhando morrendo de inveja. FALAMOS SOBRE O FILME QUE ASSISTIMOS NA SALA DE AULA. E ela gostava de coisas de romance e ficou me dizendo as coisas que ela gostava de fazer. ACABOU A AULA. Aí eu e a [Thati] fomos para a casa dela juntos dormimos juntos. EU DORMI NO COLCHÃO NA SALA. FOI MUITO LEGAL. No outro dia fomos pro colégio juntos. Fim!

(04) [Avaliação da criança - produção textual conjunta]

Miguel inicia sua produção contextualizando a proposta de escrita, possibilitando o entendimento ao interlocutor de que o relato ocorreria sobre uma situação imaginada, pautada no fato de que ele dormiria e após acordar seus desejos seriam realizados. Faltou apenas a informação de que seria necessário "pensar bem forte" para que os desejos pudessem ser concretizados; algo que seria resolvido em uma retomada do texto.

Desse modo, apoiada na proposta de produção conjunta, e considerando a escrita do gênero diário, a pesquisadora deu continuidade ao texto em primeira pessoa do singular assumindo a voz de Miguel. O tempo verbal no pretérito "Acordei" marca o início de um relato do acontecimento de um dia fictício. A pesquisadora sinalizou, inicialmente, para um evento presente na rotina de muitas pessoas, o café da manhã. Miguel, engajandose na proposta de escrita, dá seguimento ao tema "penssei bem forte e derrepente tinha o chocotone".

Ressalte-se que as ocorrências ortográficas podem ser explicadas por meio do entendimento do funcionamento da ortografia do português. $\mathrm{O}$ uso de "ss" para o verbo "pensei" se explica uma vez que na língua portuguesa o fonema /s/ pode ser representado por vários grafemas s, ss, sc, c, ç, sç, levando ao que Cagliari (2009) chama de uso indevido de letras. Tal uso é processual e faz parte das instabilidades inerentes à apropriação do sistema normativo da escrita. A criança, ao se pautar na oralidade, às vezes opta por um grafema não convencional. Da mesma forma, o de repente grafado por derrepente sinaliza para um desvio da norma bastante frequente entre os aprendizes de escrita, que é a hipossegmentação de unidades que são percebidas em bloco: derrepente, agente, defato, etc. Tais usos da língua, longe de representarem 
sinais de dificuldades de escrita, revelam indícios de reflexão sobre o objeto do conhecimento. Note-se que as ocorrências ortográficas nos textos de Miguel foram pequenas, e considerando que "não gosta de ler e escrever", questiona-se aqui como uma criança com "déficit de atenção", e que pouco lê, pode ter manifestações ortográficas mínimas. Inclusive o pensei, mais adiante no texto foi grafado conforme o padrão. Lembrando que a fixação da norma ortográfica requer o uso de memória visual, e que só memorizamos aquilo a que atentamos, dado que as funções cognitivas se inter-relacionam, reitera-se a pergunta: como uma criança com um suposto déficit atentivo pode escrever praticamente dentro da norma convencional?

Indo adiante, Miguel manifesta que após tomar café se envolveu nas suas atividades favoritas: "joguei PSP, nintendo DS, Ifhone, Smartfhone, tablet e uma metralhadora nerf". A descrição do dia, atrelada ao conhecimento de que suas vontades seriam atendidas, fez com que o menino ficasse mais voltado a manifestar seus desejos de consumo e menos em descrever, nesse momento, o envolvimento em alguma atividade específica.

Pela análise da produção é possível verificar que a sequência textual foi sendo materializada por meio de dêiticos "depois de brincar...; após comer", e, dando continuidade ao discurso, Miguel, através da elipse (pronome pessoal nulo, no caso, com valor anafórico "eu”), remete à sua entrada em sala de aula: "Entrei na sala de aula fui me sentar no meu lugar e era a minha aula preferida, que era matemática”.

No texto, o menino demonstra uma narrativa do dia de forma linguisticamente organizada, estabelecendo sequenciação temporal entre os eventos: "entrei na sala..." "fui me sentar..." permitindo o estabelecimento de sentidos por parte do leitor. Destaque para um fato de sua realidade: sua aula preferida, a de matemática. A pesquisadora continua o relato expressando a realização de exercícios em sala de aula e Miguel segue explicitando que não necessitou de auxílio neste dia: "e não precizei de ajuda de ninguém [..] e ela lá atraiz conversando". Percebe-se no trecho algumas instabilidades ortográficas: a palavra precizei, marcada com uso indevido de letras, e atraiz, que foi grafada com o apoio na oralidade devido à vocalização que faz com que haja a introdução da semivogal /i/ em parcela expressiva de variedades linguísticas faladas no Brasil. Interessante observar a utilização do pronome pessoal "ela lá atraiz" pelo qual não se consegue, apenas pela leitura do texto, recuperar o referente. Ao ser questionado sobre a referência do pronome, Miguel disse tratar-se de Mariana (uma auxiliar exclusiva que a acompanhava em sala de aula). Vale destacar que "eu lá na frente como todo mundo e ela lá atrás conversando" revela, possivelmente, 
o desejo de um afastamento, não total, uma vez que ela estaria ali "conversando", mas de um olhar constante e absoluto.

Ao escrever "A Thati veio me pedir ajuda", a pesquisadora se engajou na posição anteriormente assumida por Miguel de promover maior proximidade de uma condição relacional satisfatória. Em seguida, o menino diz "porque ela não sabia fazer o exercício e eu ajudei e depois ela me pediu em namoro e eu aceitei”, por onde é possível verificar a sequenciação estabelecida por meio de articuladores textuais que imprimem relações de causalidade. É possível observar como Miguel dispõe de conhecimentos sobre a organização textual, que permitem a progressão do tópico por meio do encadeamento tema/rema, ou seja, do acréscimo de informações novas às fornecidas anteriormente.

Do mesmo modo, consegue exprimir relações de sentido engajadas à escrita da pesquisadora. Assim, quando a pesquisadora escreve "Ficamos conversando na hora do recreio", ele dá continuidade por meio do conectivo "e" ("e os meninos ficaram olhando morrendo de inveja"). Ainda, o uso do coesivo da oralidade "aî" marca o início do desfecho: "Aí eu e a [Thati] fomos para a casa dela juntos dormimos juntos". Dando seguimento ao desfecho, Miguel reitera a repetição lexical de juntos: "no outro dia fomos para o colégio juntos", perseverando no discurso a ideia de estar "junto" com a colega, demonstrando a necessidade de uma relação mais estreita.

Apreende-se, pela leitura do texto de Miguel, que ele mobilizou uma série de conhecimentos necessários à construção de um texto: conhecimento do gênero discursivo, conhecimentos linguísticos, textuais, conhecimento de mundo, da situação de interação locutor-interlocutor, ou seja, das regras interacionais, enfim, por meio de recursos cognitivos, na atenção compartilhada com a pesquisadora, Miguel teve a chance de demonstrar como se apoia nos conhecimentos que possui para mobilizar, no uso efetivo da língua, estratégias para a construção de textos.

A respeito da constituição leitora, abaixo constam algumas considerações.

\section{A medicalização da criança e sua constituição leitora}

Durante o processo de avaliação fonoaudiológica, a pesquisadora leu para Miguel um texto: uma lenda russa intitulada $A$ divisão dos gansos, de Rosane Pamplona. Após a leitura, Miguel relatou que não havia prestado atenção, mas respondeu às perguntas realizadas. Vejamos: 
P. Você gostou?

M.[Faz sinal de mais ou menos].[..]

M. Não prestei muito bem atenção.

P. Não?

[..]

P. Você acha que quando você lê você presta mais atenção do que quando alguém lê pra você?

M. Eu tava meio agitado agora.

P. Agitado? Por quê?

M. Minha mente tava em outro lugar.

P. Onde é que tava tua mente?

M. Não sei, tava pensando em outra coisa.

[..]

P. Então, o camponês era pobre[..] ele ofereceu o ganso pro rei,o que que o rei falou?

M. Convidou ele...e pediu pra ele partir o ganso...

P. E como é que ele dividiu o ganso?

M. A cabeça pro rei, o pescoço pra rainha, as asas pra filha, as patas pro filho...

P. Então? Como é que tu não prestou atenção?

M. É porque eu sou expert em matemática.

P. Ah...então falou em divisão e você já ficou todo interessado...e como que ele justificou essa divisão?

M. Falou de dá a cabeça pro rei, que era o cabeça da casa...a rainha era o pescoço da casa...a asa pra filha, pra princesa, porque no futuro ela ia ter namorado e ia se sustentar bem...e as patas que ele[o filho] ia cuidar da casa quando o rei precisava descansar...

P. Isso mesmo. E aí o que aconteceu? O rei gostou disso?

M. Humhum...

P.E deu o que pra ele?

M. Uma moeda de ouro...bem valiosa...

P. Então, ele foi pro comércio e mostrou pra um comerciante a moeda, o que que o

comerciante fez?

M. Deu 4 gansos...

P.O próprio comerciante foi lá com 4 gansos, certo? E como é que o comerciante fez a divisão?

M. Deu um ganso pro pai, um ganso pra mãe, um ganso pro filho, um ganso pro outro filho e ele ficou sem.

P. Por que ele ficou sem? 
M. Porque ele tava pensando na moeda.

P. Ele fez a besteira e depois disse que tinha alergia a ganso. E ele ganhou a moeda?

M. Não.

P. Aí ele voltou lá pro comércio dele e o que que esse comerciante fez com o camponês?

M. Deu 4 gansos de novo...

P. E falou pra ele ir na casa do nobre?

M. Humhum...

P E daí, como é que foi?

M. Ele foi convidado de novo...e aí dessa vez ele dividiu 3 gansos pra um...não, 2 gansos pra um que soma mais um 3... 2 gansos pra mulher mais um $3 \ldots 2$ gansos pro filho mais um 3...e mais 2 pro nobre mais um 3.

P. E ele ficou com quanto?

M. Três.

P. Eram 4 gansos, certo? E 5 pessoas...aí ele pegou...juntou o marido e a mulher e "dou um ganso soma 3..." o filho e a filha, "eu dou um ganso dá $3 . .$. " e ele "eu fico com 2 dá 3 ”... daí fica 3..3..3...e o rei gostou dessa divisão?

M. Sim, deu um saco de moedas...

(05) [Avaliação da criança]

Ao analisarmos o excerto é possível verificar que Miguel prestou atenção à leitura. Mas por que revela que estava agitado? De que lugar o sujeito enuncia que não consegue, mesmo conseguindo? Há de se refletir sobre as implicações desse processo de estigmatização sofrido e seus efeitos para a formação do leitor, da relação da criança com a prática de ler.

Nessa direção, cabe a pergunta: ter internalizado uma alteração cognitiva/ atentiva, e considerando o imbricamento da ação de ler ao foco atentivo, poderia o menino se distanciar de leituras por achar que tem dificuldades de se ater a elas? Penso que, no caso de Miguel, sim. Quando da discussão do texto, ele disse que estava com "a mente em outro lugar", mesmo respondendo a todas as perguntas realizadas. Assim, "aceitar" que tem problemas de atenção pode "autorizar" a que sua mente "viaje" enquanto lê, favorecendo certo distanciamento da leitura. Ocorre que, mesmo autorizado a se desconcentrar, por conta de uma "patologia" que lhe foi atribuída, em todos os textos em que trabalhamos a leitura, Miguel ateve-se e demonstrou atenção. Assim, a relação com a leitura está atravessada por uma autoimagem rebaixada. 
Outra menção realizada por ele foi a de que estava "pensando em outra coisa", o que corrobora a suposição de que a imagem de desatento pode colaborar para uma relação menos produtiva com a leitura. Hipotetiza-se, assim, que o fortalecimento de sua autoestima, por meio da reconstituição de sua normalidade, contribuiria para a reversão de uma possível noção de mau leitor e mau escritor.

A professora de Português de Miguel foi uma das entrevistadas pela pesquisadora. Ela referiu que as condiçōes de letramento do grupo de alunos (da sala de aula frequentada por Miguel) são bastante satisfatórias e, de fato, foi observado que frequentam e leem livros na biblioteca da escola, e que, ainda, manifestam interesse pela leitura. Durante observação em sala de aula, verificou-se alguns alunos com romances embaixo da carteira e lendo, por conta própria, em momentos vagos. Em questionário aplicado à turma, buscando-se conhecer as práticas e o gosto pela leitura das crianças, constatou-se que, na maioria dos casos, são leitoras e gostam de ler também fora da escola. Miguel, entretanto, não é um leitor assíduo, tendo lido apenas um ou dois livros em forma de diário.

A mãe de Miguel disse em entrevista que é uma leitora frequente e que tentou fazer com que o filho desenvolvesse o hábito de ler por meio de determinação, o que acabou não gerando o efeito pretendido. Ademais, ela mesma se deu por conta que "a leitura vira uma coisa ruim" e acabou por implementar outra estratégia: a de pedir aos filhos para irem ao quarto antes do horário de dormir para poderem ler ${ }^{6}$. Isso mostra que a mãe valoriza a prática da leitura; valoriza, ainda, o exemplo que os pais podem delegar aos filhos, o que pode ser visto quando pede ao marido que leia "Pega um livro, nem que tu faça que tá lendo". De todo modo, mesmo assim, inserido em meios favoráveis ao desenvolvimento pelo gosto da leitura, Miguel pouco lê.

A propósito da relação com a escrita, Miguel havia mencionado que não gostava de escrever. Observemos:

P. Diz uma coisa: você tinha dito pra mim que não gostava de escrever, por que você acha que não gosta?

M. Porque é difícil...porque é difícil tipo você tem que escrever uma coisa resumida, um resumo grande, parece que vai te matar, tipo parece que vai cansar muito, que vai dar sono...

${ }^{6}$ Cabe dizer que os meninos têm cada um o seu quarto. 
P. Então você acha que é difícil escrever?

M. É. Mais ou menos...

(06) [Avaliação da criança]

Miguel descreve o que para ele representa o ato de escrever: "é difícil"; "parece que vai te matar"; "parece que vai cansar muito"; "vai dar sono", revelando uma relação de afastamento da escrita. Vale reiterar que a professora de Português do $6^{\circ}$ ano pauta sua prática em uma concepção discursiva de linguagem. Mas, em detrimento de uma prática centrada em atividades contextualizadas, Miguel, por ter vivenciado (e ainda vivenciar) um processo de medicalização, acabou desenvolvendo uma relação de sofrimento com a leitura e escrita, uma vez que para ler e escrever é necessário "manter o foco", algo que disseram a ele que não consegue.

Há de se lembrar, ainda, que unido ao processo de medicalização sofrido, Miguel, até os 6 anos de idade foi vítima de maus-tratos e depois esteve sob abrigamento, o que leva a crer que não teve experiências em eventos de letramento significativas na primeira infância; vivências essas que, conforme Lahire (2008), são responsáveis por criar nas crianças uma correlação afetiva com a leitura.

Rojo (2006), por sua vez, diz que o desenvolvimento do letramento na criança está imbricado à participação em eventos mediados pela leitura, escrita e oralidade. É esta inserção que se dá desde a tenra idade, e que ocorre principalmente em família e na escola, que faz com que a criança desenvolva e se desenvolva por meios de práticas discursivas. Desse modo, quanto mais intensas e significativas forem as vivências da criança em práticas de linguagem, mais produtivo e pleno o desenvolvimento da oralidade, leitura e escrita. Miguel teve os seus primeiros anos de vida inserido em precárias práticas discursivas. Tanto é que, segundo sua mãe, ainda aos 6 anos de idade (época da adoção) ele tinha dificuldades para falar, que pouco se entendia o que ele dizia; não sabemos se por uma questão fonética/fonológica ou se havia um atraso de linguagem mais relevante, o que é possível. Assim, apenas a partir do sexto ano de vida, Miguel teve possibilidades de inserção significativa em práticas discursivas. Rojo (2006) entende que nas práticas de linguagem que medeiam as experiências infantis estão as brincadeiras de "faz de conta". Assim, ao fazer de conta que lê e fazer de conta que escreve, a criança experimenta diferentes papéis e possibilidades, construindo o sentido social das práticas letradas. Miguel, dessa forma, "perdeu" uma fase de sua vida relevante para o desenvolvimento de uma maior valoração para com a leitura. 
Unido à questão do primeiro núcleo familiar, adentrou em uma escola (onde frequentou o $1^{\circ}$ e $2^{\circ}$ ano) que viu em suas ações "sintomas" e, portanto, perdeu outras importantes chances de desenvolver uma relação mais saudável e produtiva com a leitura e escrita.

Assim, para muitas crianças, a entrada na escola pode representar um processo de violência simbólica, nos termos de Berberian (2006), por onde se destacam as consequências para a subjetividade da criança e sua aprendizagem dentro e fora da escola. Nos poucos pareceres a que se teve acesso dos anos iniciais foram nítidas as tentativas de imposição da noção de que Miguel estava com dificuldades em se apropriar da escrita e de se "concentrar". Mesmo depois, já no $3^{\circ}$ ano, na escola de referência diagnosticado e medicado -, os relatórios da criança revelavam a condição que já havia sido imposta a Miguel. Lembremos a colocação da mãe de que a professora do $3^{\circ}$ ano "só via coisa negativa" e que o filho vivia fora da sala "tomando chazinho".

Para Berberian, Mori e Massi (2006, p. 22), "posições que, aprioristicamente, preconizam que crianças vão apresentar deficiências na aquisição da linguagem escrita, em vez de ampliar, restringem as possibilidades de efetivação de tal processo". Afirmam, ainda, que não há nada mais "antieducativo" do que desqualificar as possibilidades das crianças de se constituírem sujeitos na (e por meio da) linguagem. Contudo, mesmo submerso em algumas interações desfavoráveis na escola, o menino conseguiu vencer as barreiras pedagógicas e, apesar das dificuldades na época da alfabetização, conseguiu se apropriar da leitura e da escrita. Reitera-se, no entanto, que não tem uma relação de proximidade com as práticas de ler e de escrever. A leitura e a escrita são para Miguel atividades obrigatórias, as quais realiza para cumprir deveres escolares.

Desse modo, após realizar a avaliação fonoaudiológica de Miguel, pode-se afirmar que, considerando a história dele, a medicalização e suas implicaçôes subjetivas, a sua relação com a leitura e a escrita (o não querer se envolver, sobretudo, na prática de escrita), a queixa da professora de Português de que Miguel tem "dificuldades de sistematizar na escrita", relatado em entrevista, e levando em conta, ainda, que seu discurso escrito revela algumas marcas processuais de sua aprendizagem - que revelam a necessidade de maior inserção em práticas sociais de leitura e escrita -, o atendimento terapêutico/fonoaudiológico poderia ser indicado.

Nessa direção, se o sujeito "assume" uma visão de uma realidade que lhe é dada, e que o faz enunciar que é "diferente", "anormal", que não 
gosta de ler nem de escrever, é necessário que se reverta esse processo em meio a um embate ideológico, possibilitando, assim, à criança que sofre, a (re)construção de uma subjetividade permeada por novos sentidos. Nesse processo de ressignificação de vivências, de discursos, de valores, de crenças, de saberes, insere-se um trabalho voltado para a intensa inserção do sujeito em práticas de uso da linguagem escrita. O que se espera, por meio do atendimento fonoaudiológico, é que Miguel desenvolva uma relação mais favorável com a leitura, com a escrita, consigo mesmo.

\section{Considerações finais}

Este estudo buscou analisar a relação entre a criança com diagnóstico de TDAH e a linguagem escrita. Procurou-se refletir sobre os efeitos subjetivos decorrentes do processo de medicalização e suas implicações para a constituição leitora.

Nesta pesquisa, pudemos vivenciar parte da história de Miguel. O menino tinha histórico de abandono e maus-tratos na primeira infância, que - aliados à discursivização desfavorável no contexto escolar - levaram a processos de "desatenção" e comportamento mais ativo quando da sua entrada na escola. Nesse caso, a questão que nos move é: como os educadores lidam com a criança que se distancia daquilo que seria considerado "o ideal"? Como apontam pesquisas (DEMO, 2012), não há formação adequada que capacite os educadores para lidarem com a imensa diversidade que se apresenta no meio educacional.

Entremeadas às políticas de formação ineficiente, estão as percepções que alguns professores nutrem acerca de sua clientela. Os educadores (destaque aos pedagogos!), muitas vezes, não aceitam a diversidade manifesta nos modos de ser, pensar e agir de seus alunos e tentam impor um comportamento em conjunto. Geraldi (2013) entende, nesse sentido, que a escola precisa higienizar para homogeneizar. Trata-se de uma dessubjetivação pedagógica; "é preciso limpar o corpo dos transtornos" (p. 320). Assim, os estudantes que apresentam características distantes das idealizadas pela escola, isto é, que são mais resistentes às tentativas de dessubjetivação, são submetidos a medidas punitivas; processo que culmina na sua exclusão escolar e social.

Sabe-se que mesmo quando há problemas de cunho emocional, o aluno acolhido na/pela escola acaba por se desenvolver dentro do que seria "o esperado". Mas o que tem sido observado é que os problemas vivenciais 
da criança acabam sendo exacerbados quando vêm à tona no espaço de algumas escolas (SIGNOR, 2013a). Não se nega neste estudo que Miguel possivelmente necessite de um atendimento psicológico para tratar de sofrimentos gerados na primeira infância; o que se questiona é o papel da escola na produção da queixa; as constantes reclamaçōes que conduziram a família a buscar o "diagnóstico" e com ele todas as implicações decorrentes.

Skliar (2006) explica que os mecanismos de exclusão e inclusão seguem as mesmas diretrizes de controle individual. "O sistema que exercia o poder excluindo agora cego àquilo que acontece lá fora - e já não pode controlar com tanta eficácia - se propõe a fazê-lo por meio da inclusão ou, para melhor dizer, mediante a ficção da promessa integradora." (p. 28). O autor considera que se cria na escola a ilusão de um território inclusivo, mas é onde se exerce a exclusão dos que são pensados como anormais. Diz que, seguindo essa "lógica perversa", só podemos entrar em relação com o outro de forma objetificada em meio à modalidade do diferencialismo, em termos de tolerância, de aceitação, de respeito. E com isso, na escola, como na vida, "acabamos reduzindo toda a alteridade a uma alteridade próxima, a alguma coisa que tem de ser obrigatoriamente parecida a nós - ou ao menos previsível, pensável, assimilável”. (p. 29).

Quanto à apropriação da leitura, Miguel teve dificuldades no processo de alfabetização sem ter qualquer alteração orgânica que, por ventura, justificasse a dificuldade apresentada. Em detrimento de algumas práticas cristalizadas de ensino da leitura e escrita, pôde-se observar o quanto a visão redutora sobre a criança (e suas capacidades) tende a afetar a sua subjetividade, que tende a afetar a sua condição de aprendiz. A questão, desse modo, não se reduz a "métodos de ensino", que muitas vezes promovem estado de alheamento ao que é proposto, mas envolve, sobretudo, a concepção de sujeito, de linguagem, de ensino e de aprendizagem adotada pelos profissionais envolvidos com a educação das crianças.

Observa-se, ainda, que os efeitos subjetivos acabam atravessando a formação do sujeito enquanto leitor. Ao internalizar que é "agitada" e "desatenta", geram-se implicações que resultam no afastamento da leitura e escrita, o que pôde ser constatado por meio de análise dos enunciados proferidos por Miguel no momento da avaliação. Se ler e escrever são atividades consideradas "chatas" e "cansativas" para parcela expressiva dos alunos brasileiros - por razões delegadas às condições de produção de leitura e escrita em muitas escolas-, o que esperar de crianças que são consideradas portadoras de "transtornos" que afetariam o comportamento e a atenção? 
Se, conforme Bakhtin, a nossa ponte com a realidade nunca é direta, uma vez que é mediada por signos ideológicos, e como a significação do signo é envolto por uma dimensão valorativa, a relação com a realidade está engendrada axiologicamente. Assim, se a realidade é semiotizada, e esta foi "dada" a Miguel por meio de "gestos centrípetos" (FARACO, 2009), é esperado, então, que haja um processo de percepções desfavoráveis na relação estabelecida entre a criança e sua aprendizagem e formação leitora.

Por fim, centrando-nos não apenas em Miguel, mas nas inúmeras crianças que têm uma história parecida com a dele, e que frequentam os bancos das escolas, e que, como ele, sofrem, e que, como ele, desenvolvem uma relação ruim com a escola e com a leitura, e que, como ele, apresenta(ra)m dificuldades para se apropriar da leitura e da escrita, e que, ainda, são excluídas e estigmatizadas, acredito que há uma necessidade de reflexão sobre os problemas que se apresentam em relação à escola brasileira, possibilitando uma revisão crítica que "ocorra em uma dimensão coletiva, de preferência no interior da própria escola, envolvendo a comunidade e os educadores comprometidos com a educação e que sonham com a possibilidade de transformar o mundo através de sua ação educacional” (LEITE, 2007, p. 303).

Assim, é preciso que se socializem conhecimentos relacionados à questão da diversidade no espaço da escola, e que se construa, nesse entendimento, o sentido de Inclusão necessário à promoção de qualquer melhoria no campo da educação. A Educação Inclusiva, como explica Rodrigues (2006, p. 13, grifo meu), "constitui a promoção da formulação da educação em novas bases que rejeitem a exclusão e promovam uma educação diversa e de qualidade para todos os alunos".

\section{Referências}

BAKHTIN, M. Marxismo e filosofia da linguagem. São Paulo: HUCITEC, 2006. BARKLEY, R. Transtorno de Déficit de Atenção/Hiperatividade: manual para avaliação e tratamento. Porto Alegre: Artmed: 2006.

BERBERIAN, A. P.; MORI-DE ANGELIS, C.; MASSI, G. Letramento: referenciais em educação e saúde. São Paulo: Plexus, 2006.

CAGLIARI, L. A. Alfabetização e linguística. São Paulo: Scipione, 2009.

7 São atitudes que resultam dos discursos autoritários; das vozes que tentam impor uma única verdade: a sua própria. 
CALIMAN, L. V. Os bio-diagnósticos na era das cidadanias biológicas. In: COLLARES, C. L.; MOYSÉS, M.A; RIBEIRO, M. F. (org.). Novas capturas, antigos diagnósticos na ERA DOS TRANSTORNOS. São Paulo: Mercado de Letras, p. 119-133, 2013.

CONRAD, P. The medicalization of society: on the transformation of human conditions into treatable disorders. Baltimore: The Johns Hopkins University Press, 2007.

CUNHA, V. et al. Desempenho de escolares com transtorno de déficit de atenção e hiperatividade em tarefas metalinguísticas e de leitura. Revista CEFAC (Online), v. 15, p. 40-50, 2013.

DEMO, P. O mais importante da educação importante. São Paulo: Atlas, 2012.

FARACO, C. Linguagem e diálogo: as ideias linguísticas do círculo de Bakhtin. Curitiba: Criar Ediçôes, 2009.

GERALDI, W. Educação sem enxada e sem Ritalina: alfabeto, alfabetização e higienização. In: COLLARES, C. L.; MOYSÉS, M.A; RIBEIRO, M. F. (org.). Novas capturas, antigos diagnósticos na ERA DOS TRANSTORNOS. São Paulo: Mercado de Letras, p. 311-322, 2013.

GERALDI, W. Portos de passagem. São Paulo: Martins Fontes, 1997.

LAHIRE, B. Sucesso escolar nos meios populares : as razões do improvável. São Paulo: Ática, 2008.

LEITE, S.A.S. A construção da escola pública democrática: algumas reflexões sobre a política educacional. In: SOUZA, B. Orientação à queixa escolar. São Paulo: Casa do Psicólogo, p. 281-306, 2007.

MOYSÉS, M. A.; COLLARES, C. A. L. Dislexia e TDAH: uma análise a partir da ciência médica. In: Conselho Regional de Psicologia de São Paulo (org.). Medicalização de crianças e adolescentes: conflitos silenciados pela redução de questôes sociais a doença de indivíduos. São Paulo: Casa do Psicólogo, 2011.

MOYSÉS, M. A. A institucionalização invisível: crianças que não-aprendem-naescola. São Paulo: Mercado de Letras, 2001.

PAMPLONA, R. A árvore dos desejos. In: PAMPLONA, R; JÚNIOR, D. Outras novas histórias antigas. São Paulo: BRINQUE-BOOK, 1999.

PAMPLONA, R; GUIMARÃES, S. A divisão dos gansos. In: PAMPLONA, R: JÚNIOR, D. O homem que contava histórias. São Paulo: BRINQUE-BOOK, 2005.

RODRIGUES, D. Inclusão e educação: doze olhares sobre a educação inclusiva. São Paulo: Summus, 2006.

ROJO, R. O letramento na ontogênese: uma perspectiva socioconstrutivista. In: ROJO, R. (org.) Alfabetização e letramento. São Paulo: Mercado de Letras, p.121-173, 2006. 
SIGNOR, R. C. F.; SANTANA, A.P. A outra face do Transtorno de Déficit de Atenção e

Hiperatividade. Distúrbios da Comunicação, v. 27, n1. p. 39-54, 2015.

SIGNOR, R. Transtorno de Déficit de Atenção/Hiperatividade: uma análise histórica e social. Rev Brasileira de Linguistica Aplicada, v. 13, p. 1145-1166, 2013. SIGNOR, R. O sentido do diagnóstico de TDAH para a constituição do sujeito/ aprendiz. Tese. Doutorado em Linguística. Universidade Federal de Santa Catarina, Florianópolis, 2013a.

SILVA, M.L.Q. Desempenho em leitura e escrita de alunos com diagnóstico de TDAH. Mestrado em Educação. Curitiba: UFPR, 2006.

SKLIAR, C. A inclusão que é "nossa" e a diferença que é do "outro". In: RODRIGUES, D. Inclusão e educação: doze olhares sobre a educação inclusiva. São Paulo: Summus Editorial, p.15-35, 2006.

VYGOTSKY, L. S. Psicologia pedagógica. São Paulo: Martins Fontes, 2010. 


\section{Anexos}

\section{ANEXO 1 - Texto A árvore dos desejos, de Rosane Pamplona}

Era uma vez um homem que se queixava de levar uma vida muito difícil. Ele se achava tão injustiçado pelo destino que ele mesmo se apelidou de João sem sorte. Nada dava certo na vida de João sem sorte: não arrumava emprego, não tinha amigos, nenhuma moça se interessava por ele. Até que resolveu se matar. Comprou uma corda e quando ia se enforcar no galho de uma árvore, apareceu um velho, bem velho, com barbas brancas e longas, e disse a João:

- Você está querendo se matar, meu filho? Será que tem mesmo motivos para isso? Sente aqui perto de mim e me conte o que está acontecendo.

João contou como sua vida era difícil e, então, o velho falou:

- Sabe, meu filho, eu sou o Velho Destino e não gosto que me chamem de injusto. Por isso, vou dar uma chance a você: não muito longe daqui, existe uma árvore igual a essa, só que muito mais alta. É a árvore dos desejos. Depois de encontrá-la tudo o que você desejar se tornará realidade, basta dizer em voz alta o seu desejo. Para chegar lá você terá que caminhar durante sete dias seguindo a direção do vento. Agora seja feliz e aproveite a oportunidade do Destino!

Depois disso, o velho desapareceu. Na mesma hora começou a soprar um vento forte. João hesitou, mas acabou aceitando o desafio. Afinal, não tinha nada mais a perder. E assim fez, andou por sete dias.

Ao final do sétimo dia, ele se deparou com a árvore descrita pelo velho. Correu para perto dela e desejou:

- Quero comida e bebida à vontade!

E porque ele desejou... Uma enorme mesa apareceu à sua frente: sucos diversos, tortas, pães, frios, frutas, doces e biscoitos. Depois de satisfeito de tanto comer, João desejou novamente:

- Quero uma cama macia e travesseiro de pena!

E, porque ele desejou, seu pedido foi atendido.

No dia seguinte João desejou uma casa gigante, belas roupas, joias, carros, empregados, móveis caros para sua casa, uma bela mulher, e tudo o mais que lhe vinha à mente. $\mathrm{E}$ assim foi durante vários dias...

Até que em uma bela manhã, João acordou atormentado. Sua mulher 
já estava preparando o café da manhã que trazia na cama para João todos os dias. E ele começou a pensar: "mas que coisa estranha aconteceu comigo. Quem poderia acreditar que eu, há poucos dias atrás, era o homem mais infeliz do mundo? Aquele velho era tão esquisito. Será que ele não era um feiticeiro maligno? Acho que fui um tolo acreditando nele".

Nisso a sua bela mulher apareceu na porta do quarto com a bandeja $\mathrm{d}$ e café da manhã na mão. João olhou para a mulher e disse em voz alta.

-Só falta agora essa mulher ser um demônio e querer me devorar!

E porque ele desejou...

\section{ANEXO 2 - Texto A divisão dos Gansos, de Rosane Pamplona e Sônia Guimarães}

Ivã era um esperto camponês que, embora pobre, conseguira criar um belo ganso.

Quanto mais o ganso crescia e engordava, mais o pobre homem sonhava saboreá-lo, mas preparado com requinte, acompanhado por batatas e outras delícias e regado por um bom vinho. Porém, caindo na realidade, o camponês percebia que o máximo que seus recursos lhe permitiriam seria cozinhar o ganso em água com sal, desperdiçando, desse modo, o banquete.

Assim calculando - e ele era mesmo bom em cálculos! -, Ivã preferiu oferecer o ganso ao nobre e generoso senhor de suas terras.

Como ele bem imaginara, o nobre ficou muito agradecido pelo presente e convidou-o a partilhar de sua mesa. Na hora do jantar, o camponês viu-se rodeado por toda a nobre a família: o senhor, sua mulher, seu filho, sua filha.

$\mathrm{O}$ dono da casa convidou Ivã a proceder à divisão do ganso. Ele refletiu um pouquinho e cortou primeiro a cabeça do ganso, que colocou no prato do senhor. Em seguida, cortou o pescoço da ave e ofereceu-a à senhora. À filha couberam as asas, e ao filho as patas do ganso.

Ao presenciar tão insólita divisão, o nobre exigiu que ele se explicasse.

- É tudo muito lógico - respondeu o convidado. - O senhor, que é o cabeça da casa, merece a cabeça da ave. E quem ignora que quem sustenta a cabeça da casa, sempre lhe dando apoio, é a mulher? Por isso, a ela coube o pescoço. Sua filha, como todos esperam, deixará o lar, pois irá viver com seu futuro marido. Para lembrar esse fato, dei-lhe as asas do ganso. E ao rapaz couberam as patas, pois a ele caberá sustentar a família quando o senhor estiver na idade de descansar.

Pondo o restante do ganso no seu prato, o camponês terminou as explicações.

- E eu, que sou um pobre camponês acostumado com as sobras, fico com o resto. 
O nobre achou tão inteligente e divertida a divisão do ganso que, em vez de se irritar, deu de presente a seu convidado uma moeda de ouro.

O camponês saiu de lá muito feliz e, já no dia seguinte, dirigiu-se ao armazém da cidade para fazer suas provisões. O dono do armazém era um comerciante muito invejoso, que logo quis saber como aquele pobretão tinha conseguido uma moeda de ouro. Ivã contou-lhe o que houvera, sem omitir nenhum detalhe.

Dias depois, quem se apresentava ao nobre era o comerciante, trazendo-lhe de presente os quatro gansos que tinha. Se um ganso tinha rendido uma moeda de ouro, o que não renderiam aqueles quatro gansos - assim pensava o invejoso.

Como esperava, o dono da casa convidou-o a ficar para o jantar. E, na hora de iniciar a refeição, solicitou a seu convidado que precedesse à divisão dos gansos, lembrando de que deveria ser uma divisão justificável.

$\mathrm{O}$ comerciante contou os gansos: quatro. Contou a seguir as pessoas à sua frente: quatro. E, assim, sem muito refletir (pois sua mente só conseguia se concentrar na recompensa que receberia), pôs um ganso em cada um dos pratos, menos no seu!

Quando percebeu a bobagem que tinha feito, ficou muito envergonhado e, para se desculpar, disse que não estava mesmo com fome e que, aliás, tinha alergia a gansos. Acabou saindo de lá sem nada comer, resmungando, e também sem nada receber de presente do dono da casa, que achou aquele convidado estranho e mal-humorado.

Passaram-se uns dias e o comerciante não conseguia engolir aquele vexame. Quando viu o camponês aparecer de novo na sua loja, decidiu fazê-lo passar pela mesma situação e ofereceu-lhe quatro gansos para que ele levasse de presente ao nobre.

Ivã ficou muito contente, e assim o fez. Como era de se esperar, o nobre convidou-o a ficar para o jantar. Os quatro gansos foram preparados e todos se reuniram para saboreá-los.

O dono da casa fez a mesma recomendação: queria que os gansos fossem divididos conforme um critério lógico. $\mathrm{O}$ camponês não se atrapalhou e começou a divisão, pegando um ganso e dizendo:

- O senhor e sua esposa são dois. Mais um ganso, perfazem três.

Em seguida, pegou o segundo ganso e disse:

- Seu filho e sua filha somam dois. Mais um ganso, três.

E, trazendo para si os dois últimos gansos, terminou dizendo:

- Eu sou um apenas. Para somar três sou obrigado a ficar com estes dois.

O nobre aplaudiu a presença de espírito de Ivã e, dessa vez, presenteou-o com um saco de moedas.

Data de submissão: 10/02/2016. Data de aprovação: 20/06/2016. 